\title{
Application of Hydrodynamics in Design of Flotation Deinking Cell
}

\author{
R. G. Li ${ }^{1,2 *}$, X. F. Xie ${ }^{2}$, A. L. Wang ${ }^{2}$, K. F. Chen ${ }^{1}$ \\ ${ }^{1}$ State Key Lab. of Pulp and Paper Engineering, South China University of Technology, Guangzhou \\ 510640, China \\ ${ }^{2}$ Shandong Institute of Light Industry, Jinan 250100, China \\ Email: lrg923@163.com
}

\begin{abstract}
Recovery and recycling of waste paper has become increasingly important with demand for paper products sharply growing. The flotation process is the predominant technology for the removal of inks from waste paper because of its advantages. Flotation cells may be very different in size and shape, but the key elements ensuring aeration, ink collection and bubble separation are always present. Different aeration systems have been developed by the equipment suppliers. The hydrodynamic method, based on the self suction and mixing of air according to the Venturi principle has become the most common aeration technique. Injectors of various sizes and designs have been investigated and constantly improved and adapted to different designs of flotation units. Step diffuser is a common and predominant injector used in the flotation deinking cell.

The application of hydrodynamics in the design of step diffuser used as acration system is discussed in this paper. Turbulence strength level generated in the step diffuser has very important effect on the size and its distribution of bubbles. So, turbulence generated in the step diffuser should have appropriate strength level and scale, not only produce adequate shearing strength so as to disperse air into small bubbles but also avoid disadvantaged effect on flotation deinking efficiency. If step diffuser has a proper dimension and velocity of flow in the chambers is suitable, turbulence of suspension in the step diffuser would be in a perfect state. Structure design principles about the step diffuser were put forward in the paper according to hydrodynamics analysis, such as: number of steps, the ratio of length and diameter of a chamber, the ratio of cross section areas of next two chambers. A laboratory step diffuser used as aeration system was carried out according to the design principles.

In this paper, a laboratory flotation deinking cell installing the step diffuser was developed. The waste paper used in the experiments consisted of $75 \%$ domestic old book paper and $25 \%$ domestic old magazine. The efficiency of the deinking process was evaluated by measuring handsheet brightness and effective residual ink concentration (ERIC). By using the optimized flotation conditions, the deinked pulp brightness can reach $83.15 \%$ ISO, $10.96 \%$ ISO higher than that of the control, the effective residual ink concentration reduction is $207.39 \mathrm{mg} / \mathrm{kg}$, actual deinking efficiency is up to $59.4 \%$. The deinking experiments confirmed its superior performance of the laboratory cell.
\end{abstract}

\section{REFERENCES}

1. China Association of Paper Industry. Annual bulletin of chinese papermaking industry in 2005. China Pulp \& Paper Industry, 2006;27:12-15

2. Gu SZ. Introduction of Turbulence Heat Transition. Shanghai: Shanghai Science \& Technology Press, China, 1964

3. Bubik A., Christ A. The step diffuser-a hydraulic element in headboxes. Tappi J., 1977;60:133-137 